\title{
Editorial
}

\section{Lino Cinquini ${ }^{1}$}

Published online: 10 November 2016

(c) Springer Science+Business Media New York 2016

The year which is closing is the 20th year of life of the Journal of Management and Governance. It has been the year of transition to my new Editorship, and a challenging year of restructuring of the Boards of JMG by a notable reshuffling (see the "Editorials of editorship transition" in Issue 2, 2016).

The commitment in these demanding tasks made the planning and organization of a celebrative initiative of the first 20 years of JMG not achievable in this year, but a specific event (Symposium) is planned within the programme of the next biennal conference of AIDEA in Rome (14-15 September 2017). That will be an occasion to make the point about JMG past contribution in the field of management and governance and the paths forward that will find space in the Journal in the future.

In this Editorial of the last Issue 2016 (20th), I would like briefly but very warmly to thank all the actors that in these years have made possible the rising e affirming of JMG in the international arena of academic journals: the Italian Academy of "Economia Aziendale" that conceived the Journal, the Publisher, the three past Editors-in-Chief (Massimo Warglien, Anna Grandori, Roberto Di Pietra), the CoEditors, all the authors, reviewers, boards members that actively have contributed and "made" the Journal.

I can say that all my efforts in the next years will be to increase the value of JMG that has been built so far.

JMG Editor-in-Chief

Lino Cinquini

lino.cinquini@sssup.it

1 Institute of Management - Scuola Superiore Sant'Anna, Pisa, Italy 